This PDF is a simplified version of the original article published in Internet Archaeology. Enlarged images which support this publication can be found in the original version online. All links also go to the online version.

\title{
A four stage approach to community archaeology, illustrated with case studies from Dorset, England
}

Hayley Roberts, John Gale and Kate Welham

\section{Summary}

This article presents an approach to guide the planning, development and evaluation of community archaeology. This will assist practitioners of all forms of community archaeology by providing a pathway to ethical practice that will benefit all. The approach focuses attention on four elements that are integral to community archaeology and which should always be considered: Who (the people involved); Why (their motivation); the Archaeology (in the broadest sense, including research questions and research methods); and How (the specific format the community engagement will take). This framework is applied to three case study community archaeology projects in Dorset, England, in order to demonstrate challenging examples of planned and reflexive community archaeology.

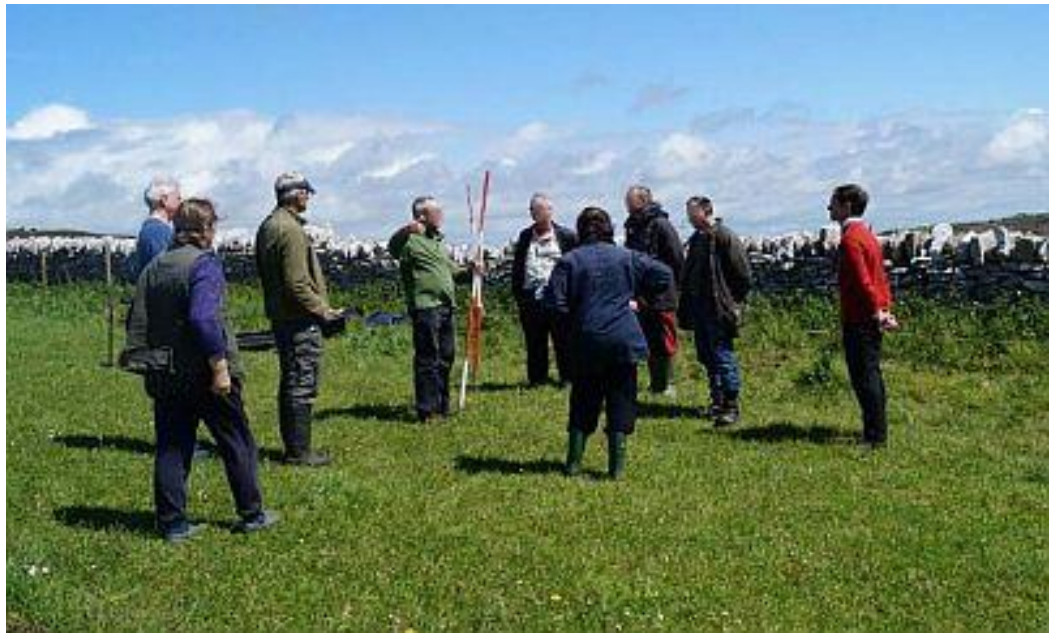

Participants learning how to conduct a resistivity survey during case study 2 . Image credit: Hayley Roberts 


\section{Introduction}

Community archaeology is an important element of archaeological practice and there are many positive case study examples. However, good practice is not guaranteed and poor practice can be extremely damaging to all involved. This has been recognised and there have been calls for critical evaluation (Gould 2016) and ethical practice (Richardson and Almansa-Sánchez 2015; Milek 2018). Several method and guidance tools for planning and critiquing community archaeology have been published, but most are limited in their application. Liddle published the first guide to community archaeology in the UK (Liddle 1985). This was written to support 'local archaeological fieldwork groups' in conducting field-walking projects. Moser et al. (2002) outlined a methodology that was later expanded by Tully (2007) who suggested seven steps that, if followed, would ensure collaborative practice. By the author's own admission these need to be reevaluated as community archaeology changes (Tully 2007, 179) and they have not, as yet, directly been re-visited.

Moshenska (2008) was quick to identify that Tully assumed an archaeology driven by academic archaeologists, not by the community; therefore, as predicted, this method is no longer always appropriate for community-led projects. As community archaeology has developed some have used Arnstein's ladder of participation (Arnstein 1969) to describe projects. Developed for the planning sector, it has been used positively within community archaeology (Belford 2011; Nevell 2013), but the purely descriptive nature of the ladder does not encourage critical reflection or directly assist with the planning or evaluation of community archaeology projects. Atalay's collaborative continuum (Atalay 2012) presents a model of 'community-based archaeology' and is also a helpful tool; but, developed in an American post-colonial and Indigenous context, it has a limited range of communities with which it can be used. This particular context does not allow projects to be entirely driven by the community without professional archaeological involvement.

The methods above predominantly assume that community archaeology should be collaborative, communities working in partnership with academic or other archaeologists; however, many archaeologists consider community archaeology to include other forms of working with communities including one-way communication, outreach and educational approaches (Roberts 2017). This article addresses concepts discussed by Milek (2018) under the name 'Open Archaeology,' including citizen science, indigenous archaeology and other forms of participatory archaeology.

Simpson and Williams (2008) published two methods for evaluating community archaeology. Both methods, which despite being important early examples of critical thinking, were essentially forms of case study reflection, with little specific guidance as to how others could repeat the exercise. Redhead (2015) also published a limited methodology for community archaeology conducted within a developer-funded context. This is a useful reminder of the possibilities of school visits, open days etc. but feels limited in its understanding as to the nuances of community archaeology.

The most encompassing guidance to date for community archaeology is that by Isherwood (2012). He suggests that community archaeology should be considered as a set of relations between three actors, and it is this framework that shapes community archaeology. These actors are the archaeological remains, heritage professionals and communities and they will vary on every site. Isherwood's model allows for variation and 
change within the practice of community archaeology, depending on the context and the specific actors involved. However the model is highly theoretical and does not provide clear practical guidance. It also assumes that heritage professionals and communities are distinct from each other. This is problematic as in practice the boundaries between these groups are unclear (Roberts 2017).

There are also many case studies of community archaeology in published and grey literature. This mass of information is problematic and unhelpful (Gould 2016, 2). Many show a lack of critical perspective, which prevents the full context of the examples from being fully understood, and this makes them problematic to apply in other scenarios and with other communities.

Community archaeology has moved beyond a theoretical discussion rooted within academia and is now a strand of archaeological practice in its own right. There were 144 job advertisements that included community archaeology skills listed on the British Archaeological Jobs Resource between 2003 and January 2019 (David Connolly pers. comm., 8 Feb. 2019). Many of these community archaeologists have called for more guidance e.g. 'Techniques which are effective for community engagement are being discovered and refined, but perhaps these findings and experiences could be better shared - we are still a long way off from having the tools we need to fully engage and explore our communities' (Grant 2014, 152).

The Chartered Institute for Archaeology Voluntary and Community Special Interest Group conducted a survey of archaeologists working in the sector and demonstrated that there 'is genuine need to support community archaeology across the sector'. A key recommendation of the report was to 'develop a strategic framework of community archaeology learning' (Brown et al. 2018, 3). This has yet to be developed. There are occasional guides to specific elements of community archaeology (such as Johnson 2018). This is clear, practical guidance to working with volunteers and is an extremely valuable resource. Breaking Ground has recently produced excellent advice for working with vulnerable groups (Breaking Ground Heritage 2020; Everill et al. 2020). There is also extensive literature on working with volunteers in other comparable sectors e.g. ecology or museums and these have been drawn further upon in the discussion at the end of this article.

The limited models and methods that focus upon collaborative approaches, uncritical case studies, and the development of the practice of community archaeology have resulted in a gap between the theory and practice of community archaeology in the UK. This has been identified across the broader public archaeology sphere by Oldham (2018). He also calls for an increase in evaluation data to improve practice.

\section{Project Aim}

This article seeks to provide an approach that can be used to guide the planning, development and evaluation of community archaeology. It focuses attention on four crucial components - Who the participants are, Why they are involved, the Archaeology, and How they intend to conduct community archaeology, i.e., the interactions between participants. This approach is the result of doctoral research and three case study examples are used to demonstrate its applicability. 
The approach to community archaeology is designed to be applicable across the sector, providing a pathway to ethical practice that benefits all; for example, by providing a framework for funding applications, or guiding best practice when including community archaeology in planning and development contexts. The approach could also be incorporated into project evaluation, where the potential for sharing and learning is high. In turn, this would increase transparency, drive up standards and reduce the occurrence of bad practice. The overarching goal in developing this approach to community archaeology is to provide guidance for anybody who wishes to conduct ethical community archaeology, in any of its guises, but also to improve ethical practice across the archaeological sector. Specific support for the many unique situations that occur in the development of individual community archaeology projects requires attention on a case-by-case basis and is beyond the remit of this article.

\section{Background and Context}

This approach to community archaeology was developed out of PhD research conducted for the explicit purpose of developing a model of best practice for community archaeology projects. Community archaeology is practiced widely across the archaeological discipline, despite being a developing specialism with limited guidance and available training, as discussed above. Many people undertake community archaeology projects and feel that they understand and know how to do community archaeology as a result of their specific experiences. Therefore, the doctoral research was repeatedly challenged and dismissed by practitioners. I was told what community archaeology is and is not (often these opinions contradicted both each other and the literature) and I was told how I should do my research. Most people did this with the best of intentions.

To eliminate this confusion and any bias I might introduce into the research, I interviewed a broad range of archaeologists to gain a rounded understanding of the current practice of community archaeology. These interviews were conducted in two case study areas: Dorset and Cambridgeshire. The method and results of these interviews are detailed in Roberts (2017). They, alongside extensive literature research, resulted in a definition of community archaeology as archaeological 'practice which involves the participation of volunteers in archaeological activities' (Roberts 2017, 80). This recognition of the broad scope of 'community archaeology' is why the guidance itself also has to be broad and general. I have also been told on numerous occasions that there is no need for broad guidance for community archaeology; however, this is directly contradicted by the calls for critical evaluation and ethical practice as discussed above (Richardson and Almansa-Sánchez 2015; Gould 2016; Milek 2018; Brown et al. 2018; Oldham 2018).

The article is a culmination of both my doctoral studies as well as nearly a decade of experience in community archaeology. The underlying doctoral research was funded jointly by Bournemouth University and the National Lottery Heritage Fund (NLHF and previously known as the Heritage Lottery Fund) through the South Dorset Ridgeway Landscape Partnership (SDRLP) which was hosted by Dorset Area for Outstanding Natural Beauty. The vision of the SDRLP was 'for a South Dorset Ridgeway that is recognised as a truly special landscape to live in, work on and to visit. One where the unique wildlife is thriving and the ancient ceremonial landscape is conserved' (Sharpe 2013, 1). 
The South Dorset Ridgeway spans 17 miles, with the town of Dorchester located to its north. It is a distinct landscape that contains an exceptional presence of prehistoric monuments; however, prior to the SDRLP local people were often unaware of its archaeological importance (Gale 2013; Sharpe 2013). One of the main aims of the SDRLP was to increase awareness of this among the local population who live and work in South Dorset.

\section{Method}

The approach to community archaeology presented here frames the design and delivery of every project according to four elements: who is involved, their motivation (why), the methods of participation (e.g. passive learning, active collaboration) and the specific archaeology. This framework developed reflexively as a result of case study projects, three of which are presented below. They are written up using this format to illustrate how the approach is intended to work. Elements of the article are written in the singular first person, reflecting the personal, direct involvement of Hayley Roberts. This is not intended to detract from the wider involvement of the co-authors.

The SDRLP and NLHF specifically required a project design that would encourage new interaction between the local community and the landscape. The development of new case study projects to test and evaluate existing methods for conducting community archaeology were written into the project design (Gale 2013). The three-year timeframe of the doctoral research meant that the case study projects had to be implemented before the full literature review and interviews (see below) were fully analysed. The case studies presented here were designed to explore methods of collaborative community archaeology and it is the results of this exploration, and the new approach that was developed as a result of it, which are reported in this article.

The three case studies were directly interlinked and based within the parish of Portesham, Dorset (see Figure 1). Portesham was selected as it is close to a variety of archaeological sites (Woodward 1983; 1991), had a large enough population to enable the research and contained a village hall that could host the first case study. Its central location at the foot of the South Dorset Ridgeway satisfied the requirements of the South Dorset Ridgeway Landscape Partnership (Gale 2013). 


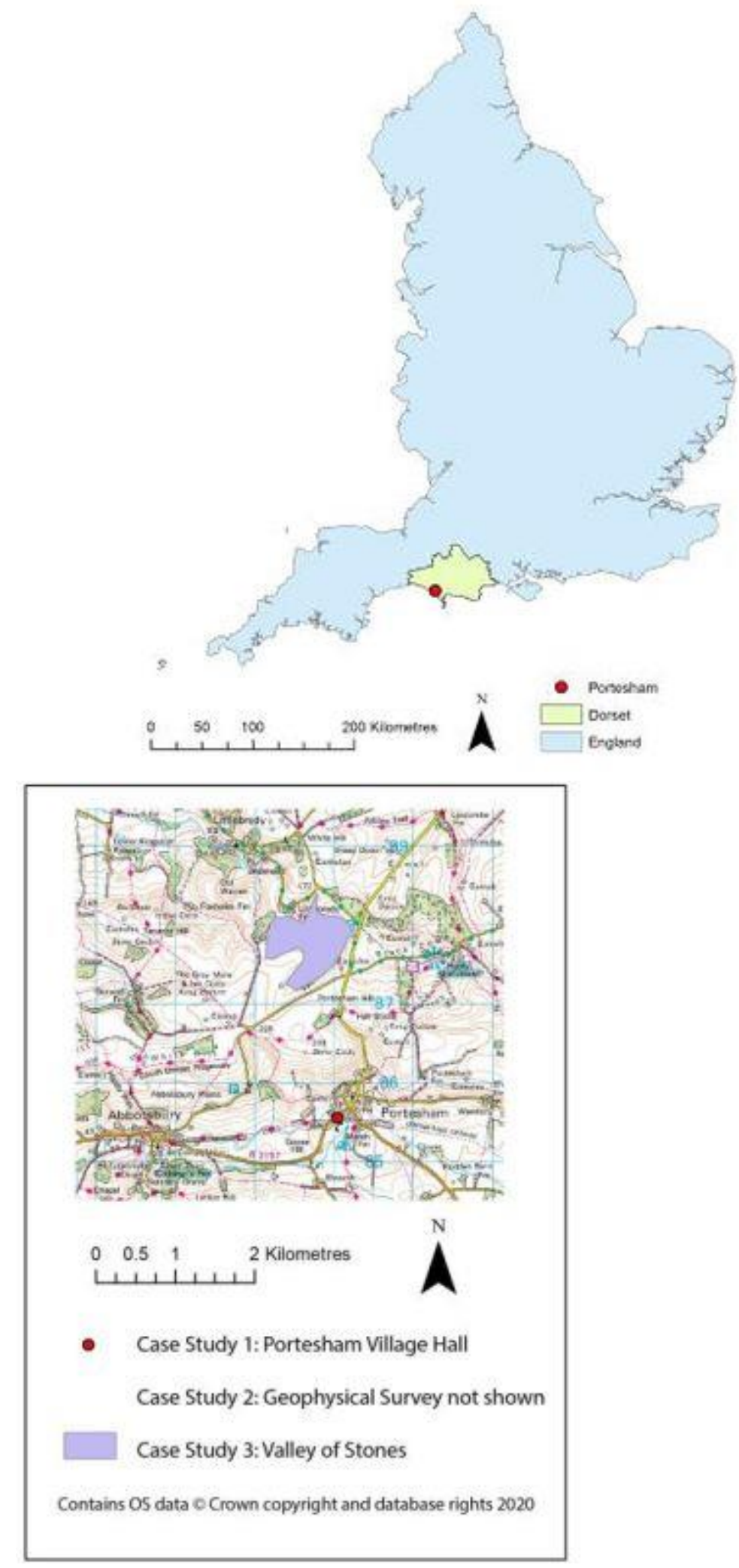

Figure 1: Maps showing the location of case studies 1 and 3 . Case study 2 was also conducted close to the village of Portesham, Dorset. Its exact location is not shown owing to the sensitive nature of the site and the wishes of the landowner 


\subsection{Case study 1: engaging a community}

\subsubsection{Project aims}

- To test the premise that community archaeology is a collaborative process

- To investigate the impact that collaboration might have on the sustainability and longevity of a project

- To establish archaeology of interest to the community and therefore select case study projects

- To gather public support for case studies

\subsubsection{How}

This project comprised three presentations that I gave to the parishioners of Portesham. The presentations were advertised through the Parish Newsletter and held in Portesham Village Hall. The content of the presentation focused upon the archaeology of the parish, explaining various sites in the landscape, but it also raised archaeological questions and suggested methods for answering them. The audience were encouraged to be interactive during the talk and then asked to provide feedback via a post-talk questionnaire. This included voting on which archaeological questions or projects they would most like to see completed. They were also invited to suggest their own projects in an attempt to counter any 'steering' from the researcher.

\subsubsection{Who}

Ninety local people attended; this was $13 \%$ of the total population of the parish, although some attendees came from neighbouring villages. There was a $57.8 \%$ response rate to the questionnaire and the range of participants is thought to be representative of the views of the event audience (the majority of tickets were booked in pairs and many couples completed the survey together). Of the respondents $34(65 \%)$ were over the age of 65 . Although it was not formally included on the questionnaire I was able to ascertain during the post-event coffee and chat, along with various follow up discussion and emails, that the archaeological experience of the audience was mixed. Some had significant archaeological knowledge although others had none.

\subsubsection{Why}

I had intended that this event would lead to further case study projects that could be used to investigate collaborative approach, two of which are discussed below. Event evaluation indicated that the audience attended out of interest in the subject matter. For some this was specifically the focus on the local area, for others it was the archaeology or the history, and for some it was the combination;

'Just moved to Dorset so interested in the archaeology and history of the area' (PiP48) 'Finding out more of the history of Portesham' (PiP32)

'Interested in ancient landscapes' (PiP40)

Some also made mention of specific archaeological features that they had interest in; 
'Information re stone circles and barrows' (PiP50)

'I live in Portesham. Fascinated by contents of burial sites' (PiP31)

The audience expressed their engagement with the subject on three different levels:

- There were those who thought that it would be an interesting but passive experience

- There were those who hoped to learn something by attending

- Those that demonstrated an interest in further involvement in archaeology

\subsubsection{Archaeology}

The presentation covered the archaeology of Portesham where I discussed well-known monuments alongside new research. I raised several key questions and outlined five potential new projects. I suggested these projects due to their association with the local area, accessibility and other financial and practical implications.

The potential projects were:

A. Geophysical and archival survey of Hampton Long Barrow (prehistoric monument) (SAM 1002868) (Colley March 1908)

B. Geophysical survey of a suspected prehistoric monument near the Hampton Stone Circle (SAM 1002694) (Dunkin 1870-71)

C. Desk-based and field assessment of prehistoric field systems

D. Archival research on prehistoric monuments. There are over 600 round barrows in the South Dorset Ridgeway, with Portesham roughly at their centre

E. Geophysical survey associated with the Portesham Mirror Burial, an Iron Age female burial with associated grave-goods (Fitzpatrick 1996)

Option $\mathrm{E}$ won the vote; the implications of this are discussed in the reflections below but it is useful to outline the proposed project in greater detail here. The mirror was initially discovered by a metal detectorist, reported and the find spot was thoroughly excavated. The mirror was one of several grave goods associated with the burial of a 1st-century Iron Age woman (Fitzpatrick 1996). The mirror is now on display in the Dorset County Museum; it is an artefact that many local people are aware and proud of. Since its discovery the landowners have looked after the find spot and they take their role as stewards of the historic environment seriously. In 2013 Amy Green, a student at Bournemouth University, conducted a geophysical investigation using magnetometry designed to 'acquire an improved understanding of the burial' (Green 2013, i). The magnetometry survey revealed a mid-Iron Age settlement; however, that research remains unpublished because the survey was incomplete and because there were unresolved questions about the relationship of the date of the burial and the date of the settlement. The earth resistivity survey I proposed as a potential community archaeology project could help answer these questions. The site was located near a limestone outcrop; if this had been used as building material an earth resistivity survey was more likely to identify it. 


\subsubsection{Reflections}

This case study project attempted to incorporate community priorities, in order to create the following collaborative community archaeology case studies. Ironically it resulted in the selection of a project that would be fully guided by university-based archaeologists (see case study 2 below). In addition, despite the presentation focus upon prehistoric archaeology (due to the original doctoral research funding proposal), many of the potential projects or research questions suggested by the audience were not prehistoric (e.g. case study 3).

Table 1: Results of vote within case study 1

\section{Potential project}

Number of votes (some of the audience voted for more than one)

Geophysical and archival survey of Hampton
Long barrow

Geophysical survey of a round barrow near the Hampton Stone Circle

Archival and ground-truthing of prehistoric field systems

Archival research on the dozens of round barrows near Portesham

Geophysical survey on land associated with the Portesham Mirror Burial

Did not vote but filled in rest of form
$7(13 \%)$

$5(10 \%)$

Audience feedback indicated three main reasons behind the attraction to this particular project.

For some it was the archaeology (the object or the burial) that was important;

'able to relate to it' (PiP1)

'greatest interest in this area, the burial provides a focus' (PiP2)

This was perhaps not surprising considering the local 'fame' of the discovery and the fact that it was a human burial with a story attached. For others it was the locality of the discovery, even if all of the other sites were technically within the parish, the Portesham Mirror was the most closely associated with the village.

'It is not far from where I live and I believe that there is more archaeology to be found' (PiP8) 
The most unexpected response related to the fact that the project would be part of wider research. Some of these answers expressed how the respondent felt that contributing to something wider was important, that it had a greater sense of purpose;

'helping to finish the project, to get a fuller picture' (PiP19)

but others were also due to the more complete story provided by my talk;

'it will contribute to a wider piece of research and there are opportunities to learn more about the wider research' (PiP6)

The community selected a site that was of importance to them, had personal and local connections, but that they felt was also going to contribute to a bigger purpose. It is likely that the comprehensive backstory to the project increased its complexity and therefore also increased its appeal, in comparison to the other projects. This could also be related to, on a personal level, by much of the audience. Lack of familiarity might also be a reason for the unpopularity of the other options in the vote (despite the background and explanation provided during the presentation), highlighting the limitations of trying to work collaboratively while within a framework (funding requirements) designed to be educational and enlightening.

\subsection{Case study 2: geophysical survey in Portesham}

\subsubsection{Project aims}

- To continue to understand the concept of collaboration within community archaeology projects through development of the outcome of case study 1

- To assess how this might influence the legacy and sustainability of community archaeology projects

- To conduct a resistivity survey to provide further context for the Portesham Mirror burial

\subsubsection{How}

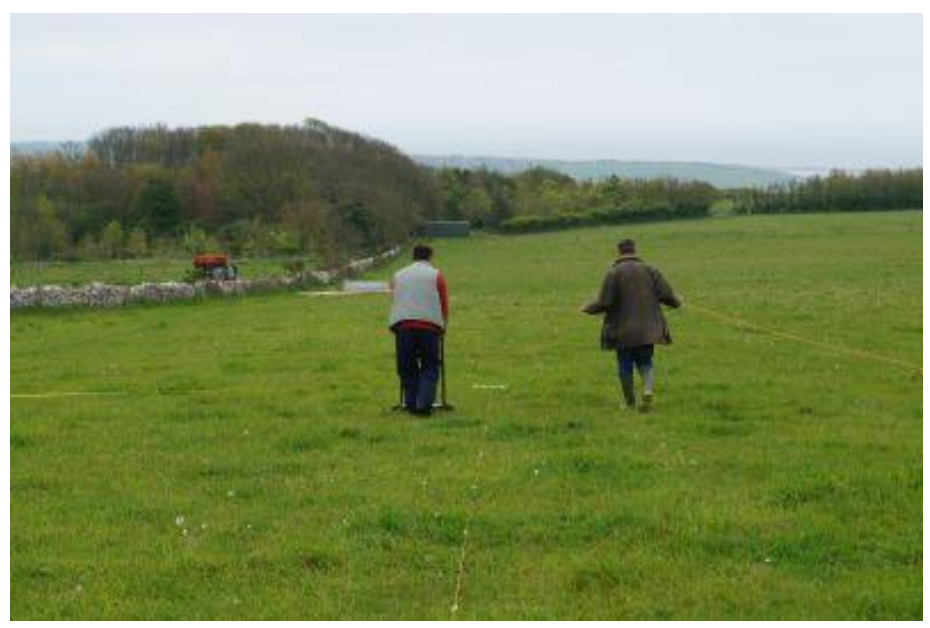

Figure 2: Case study 2: conducting resistivity survey. Image credit: Hayley Roberts 
I developed case study 2 in response to feedback from case study 1 . It was designed as a 'no experience required' event and started with a theoretical introduction. It was made clear to all participants that the project was the subject of research into community archaeology (and accordingly was fully evaluated via surveys and participant observation). Once on site the participants learnt through practical experience. At the end of each day the resistivity results were downloaded and processed. The participants were able to observe this and to see what had been discovered. On the last day this was not possible and therefore final results could not be ascertained while the participants were present. They were promised a copy as soon as possible but unfortunately there was a significant delay in providing this. Time for this project was not prioritised once the fieldwork was complete because the archaeological results were poor. A month after the survey I had received two written and four verbal requests from participants for the results. I replied to each of these, informing them that the archaeological aim of the survey had not been achieved. Despite my best intentions the full results and images were never shared with the participants (owing to local politics and priorities).

\subsubsection{Who}

The project comprised ten local volunteer participants, self-selected from the mailing list compiled after case study 1 , as well as myself and a colleague from Bournemouth University. Two of the participants were the landowners. All of the volunteer participants were over 30 but only two were over 65 . This age range was younger than that of the audience for case study 1 , possibly because of the physical requirements of the fieldwork. There were two responses to case study 1 that point towards this conclusion. When asked if they wanted to be 'kept informed about future research including the chance to get involved' they replied yes 'But now too old' and 'Regret - no car and lots of dodgy joints'. Five of the participants had never taken part in practical archaeology before. This included the landowners who, despite allowing previous research to be conducted on their land, had little understanding of the process. Six participants were members of a local archaeology society.

\subsubsection{Why}

Case study 2 was selected as the most popular project in case study 1 . As discussed above, the archaeological story was interesting, it had local relevance and the project had a wider sense of purpose.

\subsubsection{Archaeology}

A magnetometry survey (Green 2013) established that the Portesham Mirror Burial was sited within the context of a mid-Iron Age settlement. It was possible that an earth resistivity survey would provide evidence for later stone-built settlement that may not have shown up on the magnetometry survey. However, this was not the case; no new features were identified. The earth resistivity survey results are shown in Figure 3. 


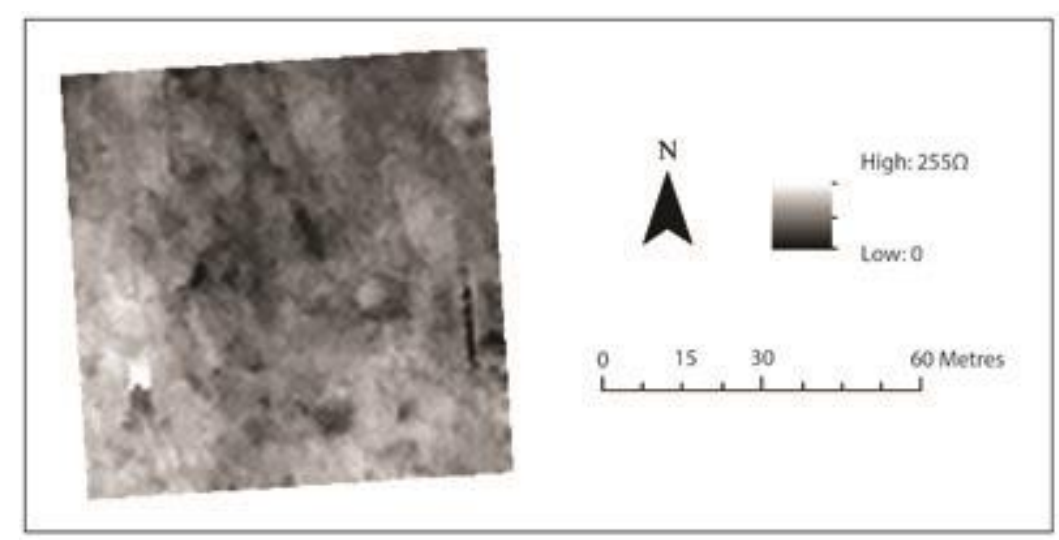

Figure 3: Results from the earth resistivity survey conducted to the north of the site of the Portesham Mirror discovery. Image credit: Hayley Roberts

\subsubsection{Reflections}

Case study 2 was an occasion where archaeologists from a university and local people connected and established a means by which they could help each other. The university had hoped to complete a research project (geophysical survey) and the participants received training in earth resistivity survey and were able to try magnetometry survey. However, due to the limited area that we were able to survey, the archaeological results did not substantially increase archaeological understanding of the site. Surveying with inexperienced participants can take significantly longer than with practised individuals. Seven of the participants wanted to be involved in further geophysical survey but they all wanted to do this with significant support and guidance, rather than taking responsibility themselves. The project was never going to be a close collaborative form of community archaeology, nor was it likely to develop into a larger research project. Fundamentally this was because the participants did not want further responsibility or involvement without additional support and training. Despite a lack of positive archaeological results the project still left an important legacy. During project planning it became apparent that the landowners were under the impression that the skeleton from the Mirror Burial was stored in an 'undignified' manner in the Dorset County Museum, and this made them feel uncomfortable. They were contemplating the idea of requesting reburial. It only took one conversation (in which the current storage situation was explained, and the ethical complications of reburial discussed) to address this situation, leaving them feeling more aware and therefore comfortable with the status quo.

One of the participants in the geophysical survey was also a member of a local archaeology group. It became apparent that they struggle to access equipment of the type we were using. A project, led by the archaeology department at Bournemouth University and in partnership with the New Forest National Park Authority, had been instigated to loan equipment to community archaeology groups. This became known as LoCATE and has supported and encouraged the group to conduct research that they might otherwise not have been able to achieve. This is a very loose form of collaboration, where the parties are not directly working together to achieve joint aims but still assist one another. There are strict rules and agreements as to the responsibilities and limitations of all parties. The requirements for insurance meant that in order to access the equipment individuals had to be part of a group or society and to have undertaken training. It is known that one of the individuals in this case study did 
join a local society in order to continue to be involved in archaeological research (not on the Portesham Mirror Burial Site).

Case study 2 demonstrated that, when community archaeology is reflexive and responsive to those taking part, relevant and appropriate legacy can result even when the original aims were not met. This can take all forms, and may be unexpected. In this example increased communication between university archaeologists and participants resulted in unexpected but very positive outputs. The particular archaeological experience of some of the participants was crucial to this; limited experience of geophysical survey but some holding membership of local archaeology societies. Understanding Who they were and Why they were participating (which was also directly related to the Archaeology) was crucial to evaluating the case study. This was integral to the development of the project i.e. How it was carried out.

\subsection{Case study 3: collaboration in the Valley of Stones}

\subsubsection{Project aims}

- To continue to understand the concept of collaboration within community archaeology projects

- To assess how this influences the legacy and sustainability of community archaeology projects

- To understand how a project of this nature develops

- To establish a date for the field systems in the Valley of Stones

\subsubsection{How}

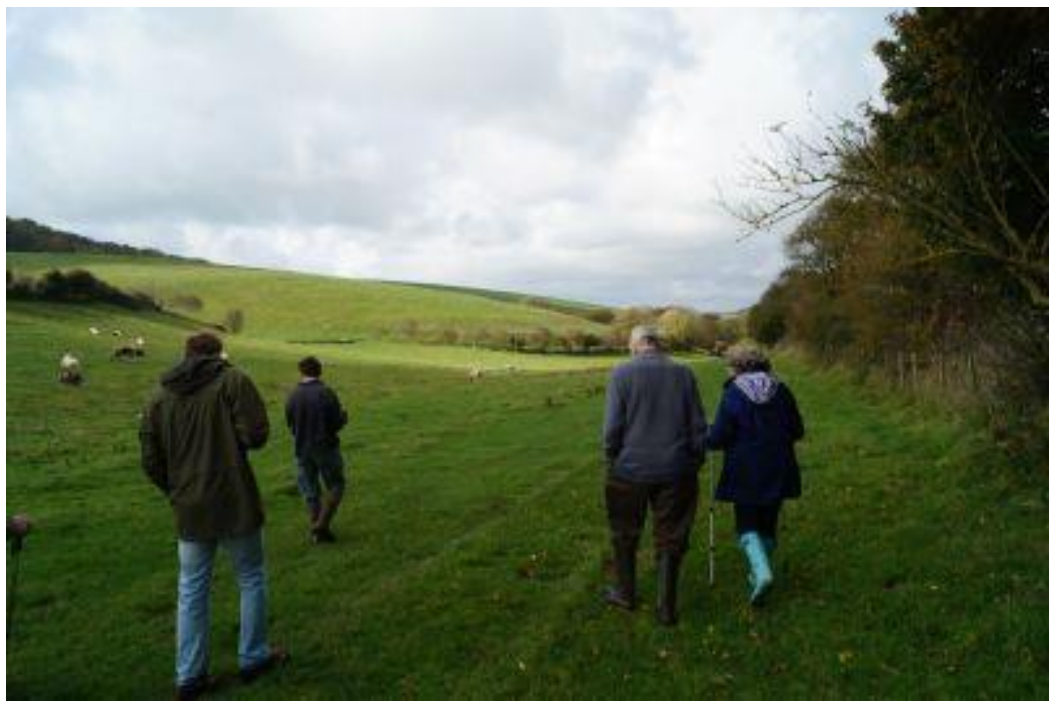

Figure 4: The participants in case study 3 during the site visit. Image credit: Hayley Roberts

This case study was proposed by a local resident after case study 1 , which I pursued as a truly community-led project. They wanted to date a well-known field system in the Valley of Stones (see Figs 1 and 4). I had hoped that this would be a collaborative 
research project, with equal input from all participants. Over the course of five meetings, beginning in March 2015, initial desk-based research was conducted by a small group of residents, and the aims and objectives were developed. The meetings were informal, during which possible options for fieldwork were discussed as well as the assets that each party could bring. Between meetings the group kept in touch via email.

Unfortunately, the structure for the group and the research overall was not set out clearly from the start. Despite starting out as a joint venture (in my eyes), as the project progressed, it became clear that the group were looking to me to provide leadership, knowledge and guidance. They saw me as an expert, but I tried to downplay this. I wanted to view them as equal contributors and therefore did not provide leadership. Unfortunately, the project ended up dissolving as I prioritised other research commitments.

\subsubsection{Who}

The group originally consisted of the proposer, three of the proposer's friends, and myself. This number later expanded to eight. Each participant had experience and personal interest in the landscape and archaeology, ranging from expertise in aerial photography to botany. One participant owned nearby land on which there are similar earthworks.

\subsubsection{Why}

At the outset it was clear that the group saw this project as a way to access physical resources, and in return they would be subjects for my doctoral research into community archaeology.

\subsubsection{Archaeology}

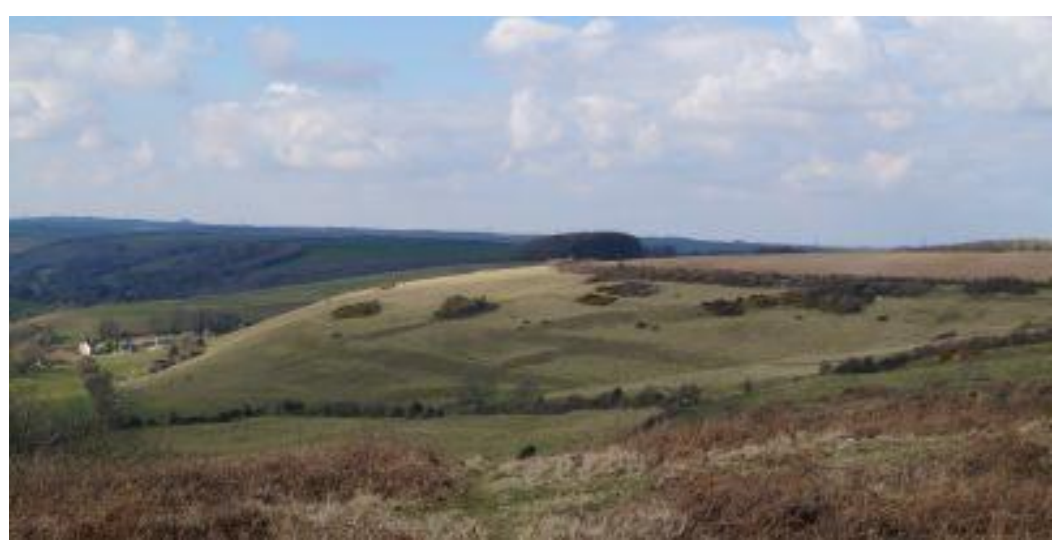

Figure 5: Valley of Stones field system. Image credit: Hayley Roberts

The Valley of Stones is a Scheduled Ancient Monument (No. 1002431). It contains significant upstanding earthworks that are predominantly field systems (both prehistoric and later) but also include hut circles and other enclosures. The team initially proposed that the project would try to date the field systems using environmental coring and radiocarbon dating. I expressed a concern that this might not be possible; not only would 
it require permission from Historic England but the chance of encountering datable material was very low and without excavation any dating achieved would lack context. The group were keen to progress anyway, so we proceeded with desktop research. Fieldwork did not follow.

A variety of traditional and non-traditional research resources were accessed by the group in order to inform the project. There was no deliberate allocation of the background research within the group; however, each member investigated a different area according to their previous experience. These included the Historic Environment Record, landowners archive and published literature. One group member also used another method of research. After reading various documents, often online, they would send emails to people they hoped would have knowledge of the subject in order to gather further knowledge or clarity e.g.

'I wondered if you had any suggestions about what we could do that might shed some light on who might have created and used these fields' (excerpt of email to a Heritage Miller 11/09/2015)

These emails, combined with the reading material discovered and the archives investigated, demonstrate the range of resources that are available to community archaeology groups. It is obvious that community groups have restricted access to published material (usually due to paywalls), but in this example they accessed a range of other resources.

\subsubsection{Reflections}

One of the dilemmas encountered by the project was that the site in question was a Scheduled Ancient Monument and therefore permission had to be requested from Historic England in order to conduct any below-ground fieldwork. Unfortunately this was what the group had proposed. The key to unlocking access to the site was through official channels and I, as a professional archaeologist, was seen as best placed to judge whether it was worth applying, since I knew more about the system. This served to highlight the different resources and knowledge to which I had access and the other participants did not. Although it is unclear whether they saw this project as a potential way around these restrictions, the group certainly saw it as a way of getting access to other resources (using students as labour force, and coring equipment) while offering certain things themselves (funding for radiocarbon dating). This, along with lack of any formal group structure, highlighted inequality and power relations within the group, which I had initially (perhaps naively) hoped would be collaborative and equal. In this particular example the unclear power relationship did not cause harm; however, it demonstrates why transparency and clarity in community archaeology projects is important.

Traditionally, this case study would never be published because it can be seen as a failure on two levels; no new archaeological knowledge was discovered, nor did the project result in any positive long-term community impact. However, by following this approach the project can be critically assessed, shared and learnt from. Despite apparent failure, important insights into community archaeology have been highlighted. It can also be seen that if all elements had been openly discussed as part of the project development it may have been more successful in answering research questions. Understanding the participants, and why they were participating in this project, was 
fundamental to understanding the relationship between individuals, which led to the development (or lack of) this community archaeology project.

\section{Discussion}

These three case studies are unusual examples of published community archaeology; they did not have high impact outcomes, they did not establish exciting new archaeological knowledge and they did not demonstrably improve the lives of participants. Despite this, they highlight important elements of the practice of community archaeology. In case study 1 the Portesham Mirror geophysical survey won the vote. This was not just because it had a relatable and relevant story but participants also felt that it had a greater sense of purpose. In case study 2 the participants demonstrated that they did not want the responsibility, or having the experience required, to take the project further. Instead the success of this case study was demonstrated by the unexpected, smaller legacies. Case study 3 demonstrated problems with power relations between professional archaeologists and volunteers, particularly when working with professional structures such as Historic England.

All three case studies demonstrate that assumptions cannot be made regarding those involved in community archaeology and their motivation. They also demonstrate that collaborative approaches are not always the most appropriate method of community archaeology and highlight the need for thorough evaluation. This emphasises the gap between theoretical guidance and the practice of community archaeology, at least in the UK and which this article seeks to address.

These outcomes were identified by reflecting critically back upon the case studies through four elements: How, Who, Why and the Archaeology. These provide the framework for the approach we present here to guide best practice in community archaeology. The approach can be used to plan and evaluate all community archaeology projects. The following discussion helps to demonstrate why these four components are crucial when planning and evaluating community archaeology.

\subsection{How}

How community archaeology is conducted has more to do with the interactions between participants than with archaeological methods. This has often been a central theme within theoretical debate regarding what constitutes community archaeology (Grima 2016; Isherwood 2012; Jones 2015; Marshall 2009; Roberts 2017; Simpson 2009; Smith and Waterton 2009; Thomas 2014) and this doctoral research was no different. In order to test different methods of community archaeology a variety of relationships between communities and the researcher and between the participants themselves had to be established. Each case study presented here was planned and developed in a unique way according to those who took part, their motivations and the archaeology involved. The first was an interactive presentation, the second a participatory field project and the third was a fully immersive collaborative project. Initially these were attempts to create a form of community archaeology with a high level of involvement from participants, but they did not develop as expected. In case study 1 the outcome of the vote (which became case study 2) indicated that involvement in a bigger project was more important than responsibility. In case study 2 , lack of experience and 
skills of the participants was a major factor in preventing the project from developing further. Instead the legacy was realised through existing groups and societies.

Communication is key within any successful relationship, and that includes those involved in community archaeology. The way in which participation happens is a very important part of community archaeology and it can take many forms; from 'teaching' i.e. one-directional knowledge - through to collaborative and partnership working. The methods used for interactions between participants are crucial for the success of any project. It is also extremely important that methods are openly planned, discussed and reviewed to ensure that all participants are aware of the situation. It is also important to acknowledge these forms of communication because they are often ways in which power differentials are expressed.

In community archaeology in the UK, the perception of professional archaeologists or, as in case study 3, those with access to professional systems, could be seen to hold power over those who do not. This makes up part of the authorised heritage discourse $(\mathrm{AHD})$ :

'The authorised heritage discourse focuses attention on aesthetically pleasing material objects, sites, places and/or landscapes that current generations 'must' care for, protect and revere so that they may be passed to nebulous future generations for their education, and to forge a sense of common identity based on the past' (Smith 2006, 29).

The AHD also refers to the development of the archaeological profession, which has become the voice that controls, manages and records the material culture of the past (Belford 2011; Roberts 2017).

By investigating different methods of participation in community archaeology the doctoral research developed into an exploration of these power relationships. Despite the research being conducted with openness to community perspectives (they could select, and steer the projects) the participants all wanted to follow the authorised heritage discourse. In case study 1 the most popular project was one led by a university, and in case study 2 the participants did not want to continue the project with their 'limited' experience. They would rather join an existing archaeology society or group. The dynamic between professional archaeologists and other individuals taking part was most apparent in case study 3 . Although case study 3 was intended to be about equality and collaboration - i.e. each participant was equally important when working together, and all participants were specifically involved in the development of the project, there was still a power differential created by the knowledge and resources that the researcher had access to and the local people did not. Despite willingness to try something different, this case study was limited by the AHD in the form of a scheduled monument and the desires of the participants to use the professional archaeologist to access this.

Community archaeology is often discussed in terms of inclusivity, of openness and accessibility. However, it is not necessarily just the professional archaeologists who wish to conform to the AHD but the public community themselves also place importance on this. This, in turn, is linked to complex questions of power and identity. 


\subsection{Who}

Communities are not homogeneous, simple or static (Marshall 2002; 2009;

Pyburn 2011). However, community is a word that has become important in political discourse and this has permeated into the management structures of the archaeology and the historic environment (Sayer 2014; Isherwood 2009; 2012; Jones 2015).

[W]ithin a world that has been perceived to have become less secure, much as a consequence of growing privatisation and globalisation, the idea of 'community' has acquired growing attraction within society. 'Community' has come to be seen as a warm and cosy place (Isherwood 2012, 9).

Community is a word often used without scrutiny, which, as discussed above, can result in a power imbalance between archaeologists and others (Smith 2015; Roberts 2017; Milek 2018). In order to prevent issues of misuse or misunderstanding it is essential to consider the perspective of every participant, from the organisers and funders through to the smallest contributor. Respectful dialogue should reinforce concepts of equality or highlight inequalities. It will also allow complexity and fluidity within communities to be recognised.

In the three case studies the participants were a crucial part of each project and contributed to its development. They had personal attachments to the locale and therefore the projects. In case study 1 the participants were typical of a southern English community archaeology audience (see Roberts 2017 for more reasoning). At the time this appeared to be reasonable when testing models of community archaeology; however, in hindsight it can be seen as problematic. The way in which the three case study projects developed from each other, and the fact that participants were selfselected, limited the involvement of audiences new to archaeology. This was as a result of the funding situation and research method (developing case studies in a particular location and with specified local populations). Archaeology as a discipline is not diverse (Aitchison and Rocks-Macqueen 2013; Thomas 2010), and often struggles to include a wide audience. Community archaeology has an important role to play in addressing this issue, not only through engaging new audiences, but also through listening and reflecting on reasons why the subject appears exclusionary. However, community archaeology is often not diverse and, as these case studies demonstrate, this can often lead to reinforcing the AHD, rather than challenging it. This paradoxical situation has also been acknowledged by Belford (2014) and Carman (2011). It is important for community archaeology to acknowledge who it includes, who it doesn't include and why this is. This is important from an ethical perspective and is intrinsically related back to the discussion of what is, or isn't, community archaeology.

\subsection{Why}

The changing nature of community archaeology and its elusive definition are testament to the multiple motivations behind community archaeology. For example, the tendency of archaeology to emphasise the positive social and well-being impacts of community archaeology is commonplace (e.g. Simpson 2010; Kiddey and Schofield 2011; Cole 2012; Sayer 2014; Big Heritage 2015; Finnegan 2016). In this case the main motivation behind the case study projects was to explore methods of communuity archaeology as part of doctoral research. 
Individual participants are also driven by a variety of altruistic and self-directed factors. This is evident in many different types of volunteering, from citizen science (Hobbs and White 2012; Raddick et al. 2013; Stukas et al. 2016), to ecological management (King and Lynch 1998), to health care and the emergency services (Carpenter and Myers 2010; Mundle et al. 2012), and arts and sport (D'Souza et al. 2011) but has only recently been discussed with regard to community archaeology by Johnston who makes an important recommendation: 'Don't make assumptions about people' $(\underline{2018}, 12)$.

Sense of purpose was an important element in the selection of, and participation in case study 2 . This is a common motivation for individuals and this has been directly linked to the well-being benefits of volunteering (e.g. Hobbs and White 2012; Stukas et al. 2016). Within museum studies two theoretical models of volunteer management can be identified that consider motivation behind volunteering (Holmes 2003,353 ). These are the economic model, where the volunteer is seen as an unpaid worker and the leisure model where the volunteer is seen as a highly engaged visitor. The case studies above demonstrate that although both models can be applied to community archaeology, the option that volunteers might prefer to have a more passive experience should also be considered. The fact that collaborative approaches were not necessarily the best methods to have used in the case studies above helps to demonstrate this although can make it harder to understand the best way in which a project should develop, particularly to diversify subject and audience. If you understand the motivation for participation in community archaeology the project can be tailored to increase chances of successful outcomes.

Since community implies the notion of belonging, community archaeology is often claimed to help individuals feel included. The Homeless Heritage Project was a particularly strong UK example that focused on an often excluded community (Kiddey and Schofield 2011). However, when community archaeology only incorporates the $A H D$, as these doctoral case studies do, it could have the opposite effect and create feelings of exclusion. This is comparable to Belford's sustainable archaeology. Belford claims that successful social sustainability within community archaeology is most likely to be achieved when 'participants are not drawn from the margins, but from the mainstream majority of property-owning, tax-paying and law-abiding citizens. This is not to say that community archaeology should only involve such people, but for projects to be sustainable over the long term they need to be at the core' (Belford 2014, 32). This, however, implies that community archaeology projects that do not have significant participation by this sector of society will not have long-term impact and cannot therefore have social sustainability. This argument assumes that sustainability equals impact, and that impact cannot be achieved without sustainability. This is not necessarily true but is much harder to prove. It also suggests that diverse community archaeology is unlikely to be sustainable. If this is true, community archaeology has a fundamental problem. This is particularly problematic when community archaeology is also used to justify the existence of the archaeological profession. We then have to ask ourselves how community archaeology can be willing to relinquish control, to listen to other perspectives of the past while using the same mechanism to reinforce our own? A reflexive methodology, i.e. listening to a diverse audience and incorporating their perspectives, cannot be possible if the objectives are ultimately to reinforce the status quo. Understanding the motivation of all participants in community archaeology, from inexperienced volunteers, to amateur archaeologists in local archaeology societies, to professional archaeologists, project managers and funders should be a central premise to any community archaeology project. 
This contradiction underlies the doctoral case studies, and the project design. The research needed to get people involved, and tried to include their perspectives; it tried to relinquish control, but was unable to do so. In all three case studies, the participants valued the experience and expertise of 'the professional'. In Case study 1, the vote was heavily influenced by the involvement of a university in the geophysical survey, which gave it a greater sense of purpose. In Case study 2, lack of experience and access to equipment prevented any participants from wanting to continue the project. In case study 3 the PhD researcher was seen as 'the expert' despite trying to place equal value on all participants.

With hindsight it can be seen that in this context fully collaborative research was not the best approach to have taken, and perhaps this helps to highlight the gap identified at the start of this article between the majority of published guidance on community archaeology (which mainly describes collaborative research) and the reality of practice within southern England. Perhaps more could have been achieved if the researcher had been more willing to act as an authority, while taking the perspective of local people into account.

\subsection{Archaeology}

The archaeological landscape of Dorset was at the centre of the three case study projects discussed here. Community archaeology is about the people of the past as well as the present; it is important that the archaeological research is rigorous, and addresses specific research questions. Failure to conduct rigorous research is one potential criticism of community archaeology; however, when the research is conducted properly this will be unfounded (Atalay 2012, 74).

Community archaeology can help to ask and answer questions that the AHD might not otherwise consider. In the UK significant levels of research are conducted by community-based groups; Hedge and Nash (2016) estimated 20,000 research outputs between 2010 and 2015. Research topics and methods are selected according to the Who and the Why of community archaeology and, therefore, are wide ranging and may not be those typically considered by academic archaeologists (Thomas 2010; Hedge and Nash 2016; Roberts 2017). Case study 3 was an example of this. The participants didn't believe that the field systems in the Valley of Stones were all Celtic in date, as stated by the formal interpretation.

Assumptions regarding subjects of interest should not be made when conducting community archaeology. It is very important to consult the community and consider their motivation. The nature of the archaeology will also influence the type of community archaeology conducted; it will affect practical elements as well as influencing how participants achieve their aim. Working alone within an archive, for example, is likely to provide a different set of well-being outcomes to a social, outdoors project.

\section{Conclusion}

The case studies in this article have been used to demonstrate critical evaluation of community archaeology through an approach that uses four key components - how, who, why and the archaeology. It helped the authors understand and demonstrate that collaborative approaches to community archaeology are not always the most 
appropriate methods of participation and that assumptions cannot be made about participant motivation. The approach can be used to encourage informed project development, execution and evaluation but it is not to be considered a strict guide, followed step by step, but rather used to provoke and stimulate considered practice; answers to one question are likely to alter the answers to another. It does not claim to include every question that should be considered when conducting community archaeology, rather the themes should be seen as a starting point. Reassessment, reevaluation and reflection during the course of any project will also be crucial to success. This approach to community archaeology helps to avoid judging projects or events but places importance upon viewing each in context. Transparency will ensure that communities are not misled or misrepresented, participants are fully satisfied, and that the archaeological record can receive maximum benefit. This is particularly important when trying to conduct community archaeology in an ethical manner.

It is hoped that this approach will be taken as guidance, rooted in both practical and theoretical understanding, to support the practice of community archaeology. Not all projects will have revelations in all four categories, and there are many more ways in which participants, their motivations, the archaeology and their interactions can be understood than outlined here. It is not the place of this research to outline every ethical possibility for every project and it is essential that further advice is taken for many of these. For example, gathering demographic data needs to be conducted very carefully. The approach outlined in this text will need to be supported by further guidance and specific support, owing to the huge diversity of communities and activities that community archaeology incorporates, which is beyond the scope of any one article.

This approach will only be a useful tool if followed with an open mind and the elements constantly reconsidered as projects develop. It was designed to guide best practice for community archaeology in a UK context; however, owing to its thought-provoking nature it may also be applicable in other contexts and cultures. Community archaeology will continue to be political and develop in response to social contexts and this approach will act as a guide to help it openly navigate the future.

\section{Acknowledgements}

Many individuals have contributed to this work through participation in the case study projects and we are grateful for all their time and patience. They are not all mentioned by name to ensure anonymity, but this does not diminish our appreciation for their help. In particular we would like to thank the National Lottery Heritage Fund and Heritage Lottery Fund Players, Dorset County Council, Dorset Area for Outstanding Natural Beauty, the South Dorset Ridgeway Landscape Partnership and Bournemouth University for funding and enabling this research. Alex Pryor and the anonymous reviewers significantly contributed to the development of this article.

\section{Bibliography}

Aitchison, K. and Rocks-Macqueen, D. 2013 Archaeology Labour Market Intelligence: Profiling the Profession 2012-13, Sheffield: Landward Research. https://www.landward.eu/2013/10/archaeology-labour-market-intelligenceprofiling-the-profession-2012-13.html [Last accessed: 21 May 2020]. 
Arnstein, S.R. 1969 'A ladder of citizen participation', Journal of American Institute of Planners 35(4), 216-24. https://doi.org/10.1080/01944366908977225

Atalay, S. 2012 Community-Based Archaeology: Research with, by, and for Indigenous and Local Communities, Berkeley: University of California

Press. https://doi.org/10.1525/9780520953468

Belford, P. 2011 'Archaeology, community, and identity in an English New

Town', Historic Environment-Policy and Practice 2(1), 49-

67. https://doi.org/10.1179/175675011X12943261434602

Belford, P. 2014 'Sustainability in community archaeology,' Online Journal in Public Archaeology, Special volume, 21-44. https://doi.org/10.23914/ap.v4i2.58

Big Heritage 2015 Dig Blacon: health evaluation, Chester: http://bigheritage.co.uk/files/2015/07/Dig-Blacon-Health-Evaluation-20161.pdf [Last accessed: 22 June 2018].

Breaking Ground Heritage 2020

[website] http://www.breakinggroundheritage.org.uk [Last accessed: 17 June 2020].

Brown, J., Miles, D. and Partridge, A. 2018 Voluntary and Community Special Interest Group Community Archaeologist Survey Report, Chartered Institute for

Archaeologists. https://www.archaeologists.net/news/voluntary-and-community-specialinterest-group-community-archaeologist-survey-report-1541761016 [Last accessed: 22 August 2019].

Carpenter, J. and Myers, C.K. 2010 'Why volunteer? Evidence on the role of altruism, image, and incentives', Journal of Public Economics 94, 911-

20. https://doi.org/10.1016/j.jpubeco.2010.07.007

Carman, J. 2011 'Stories we tell: myths at the heart of "Community

Archaeology"', Archaeologies 7(3), 490-501. https://doi.org/10.1007/s11759-011-9180-x

Cole, T. 2012 'The Stanwell Mothers Project: reaching archaeologists and communities' in G. Moshenska and S. Dhanjal (eds) Community Archaeology. Themes, Methods and Practices, Oxford: Oxbow Books. 71-79. https://doi.org/10.2307/j.ctvh1dn3q.13

Colley March, H. 1908 'The ritual of barrows and circles', Proceedings of the Dorset Natural History and Archaeological Society 29, 225-50.

D'Souza, J., Low, N., Lee, L., Morrell, G. and Hall, J. 2011 Understanding the drivers of volunteering in culture and sport: analysis of the Taking Part Survey, National Centre for Social Research, Commissioned by The Culture and Sport Evidence (CASE).

Drake, J.C. and Fahy, A.M. 1987 Guide to Archaeology on Community Programme, Birmingham, Institute for Archaeologists, Occasional Paper 2.

Dunkin, E.H.W. 1870-71 'Some account of the megalithic remains in South Dorset', The Reliquary Quarterly Journal and Review 11, 145-57. 
Everill, P., Bennett, R. and Burnell, K. 2020 'Dig in: an evaluation of the role of archaeological fieldwork for the improved wellbeing of military veterans', Antiquity 94(373), 212-27. https://doi.org/10.15184/aqy.2019.85

Finnegan, A. 2016 'The biopsychosocial benefits and shortfalls for armed forces veterans engaged in archaeological activities', Nurse Education Today 47, 1522. https://doi.org/10.1016/j.nedt.2016.03.009

Fitzpatrick, A.P. 1996 'A 1st-century AD "Durotrigian" inhumation burial with a decorated Iron Age mirror from Portesham, Dorset', Proceedings of Dorset Natural History and Archaeological Society 118, 51-70.

Gale, J. 2013 Perceptions of Prehistory: A project brief and outline specification for the implementation and delivery of a community based archaeological project and PhD studentship that examines the sustainability and best practice of community based archaeological projects, with a case study using the landscape and communities of the South Dorset Ridgeway as a geographical focus, Circulated typescript: Bournemouth University.

Gould, P.G. 2016 'On the case: method in public and community archaeology', Public Archaeology 15, 1-18. https://doi.org/10.1080/14655187.2016.1199942

Grant, K. 2014 'Canals, cake, and 6H pencils: starting out in community archaeology', Journal of Community Archaeology and Heritage 1(2), 137-

54. https://doi.org/10.1179/2051819614Z.00000000010

Green, A. 2013 An investigation into the context of the Portesham mirror burial through geophysical survey of the surrounding area, Unpublished Undergraduate Thesis, Bournemouth University.

Grima, R. 2016 'But isn't all archaeology "public" archaeology?', Public Archaeology 15(1), 50-58. https://doi.org/10.1080/14655187.2016.1200350

Hedge, R. and Nash, A. 2016 Assessing the Value of Community Generated Historic Environment Research, Historic England and Worcestershire County Council. https://historicengland.org.uk/research/support-and-collaboration/researchframeworks-typologies/assessing-community-generated-research [Last accessed: 13 December 2018].

Hobbs, S.J. and White, P.C.L. 2012 'Motivations and barriers in relation to community participation in biodiversity recording', Journal for Nature Conservation 20, 36473. https://doi.org/10.1016/j.jnc.2012.08.002

Holmes, K. 2003 'Volunteers in the heritage sector: a neglected audience?', International Journal of Heritage Studies 9(4), 341-55. https://doi.org/10.1080/1352725022000155072

Isherwood, R. 2009 Community Archaeology. A study of the conceptual, political and practical issues surrounding community archaeology in the United Kingdom today, Unpublished PhD thesis, University of Manchester. 
Isherwood, R. 2012 'Community archaeology: conceptual and political issues' in G. Moshenska and S. Dhanjal (eds) Community Archaeology. Themes Methods and Practices, Oxford: Oxbow Books. 6-17. https://doi.org/10.2307/j.ctvh1dn3q.6

Johnston, H. 2018 'Guide 51: Working with volunteers on archaeology projects', BAJR Guides, http://www.bajr.org/BAJRGuides/51 Volunteering/Guide 51 Managing Volunte ers.pdf [Last accessed: 21 May 2020].

Jones, S. 2015 'Archaeology and the construction of community identities' in M.D. Nevell and N. Redhead (eds) Archaeology for All. Community Archaeology in the Early 21st Century: Participation, Practice and Impact, Salford: University of Salford. 3-14.

Kiddey, R. and Schofield, J. 2011 'Embrace the margins: adventures in archaeology and homelessness', Public Archaeology 10(1), 4-

22. https://doi.org/10.1179/175355311X12991501673140

King, K.N. and Lynch, C.V. 1998 'The motivation of volunteers in the nature conservancy - Ohio Chapter, a non-profit environmental organization', Journal of Volunteer Administration 16(5), 5-11.

Liddle, P. 1985 Community Archaeology- A Fieldworker's handbook of organisation and techniques, Leicester: Leicester Museums Art Galleries and Records Service.

Marshall, Y. 2002 'What is community archaeology?', World Archaeology 34(2), 21119. https://doi.org/10.1080/0043824022000007062

Marshall, Y. 2009 'Community archaeology' in B.W. Cunliffe, C. Gosden and R.A. Joyce The Oxford Handbook of Archaeology, Oxford: Oxford University Press. 10781101. https://doi.org/10.1093/oxfordhb/9780199271016.013.0035

Milek, K. 2018 'Transdisciplinary archaeology and the future of archaeological practice: citizen science, portable science, ethical science', Norwegian Archaeological Review 51(1-2), 36-47. https://doi.org/10.1080/00293652.2018.1552312

Moser, S., Glazier, D., Phillips, J.E., Nasser el Nemr, L., Mousa, M.S., Aiesh, R.N., Richardson, S., Conner, A. and Seymour, M. 2002 'Transforming archaeology through practice: strategies for collaborative archaeology and the community archaeology project at Quseir, Egypt', World Archaeology 34(2), 220-

48. https://doi.org/10.1179/pua.2000.1.1.21

Moshenska, G. 2008 'Community archaeology from below: a response to Tully', Public Archaeology 7(1), 51. https://doi.org/10.1179/175355308X306004

Mundle, C., Naylor, C., Weaks, L., and Buck, D. 2012 Volunteering in health and care in England, The Kings

Fund. https://www.kingsfund.org.uk/sites/default/files/field/field publication file/volunteer ing-in-health-and-social-care-kingsfund-mar13.pdf [Last accessed: 13 December 2018].

Nevell, M.D. 2013 'Archaeology for all: managing expectation and learning from the past for the future - The Dig Manchester Community Archaeology Experience' in C. Dalglish (ed) Archaeology, the Public and the Recent Past, Boydell Press. 65-76. 
Oldham, M. 2018 'Bridging the gap: classification, theory and practice in public archaeology', Public Archaeology 16. https://doi.org/10.1080/14655187.2017.1499398

Pyburn, K.A. 2011 'Engaged archaeology: whose community? Which public?' in K. Okamura and A. Matsuda (eds) New Perspectives in Global Public Archaeology, New York: Springer, 29-41. https://doi.org/10.1007/978-1-4614-0341-8 3

Raddick, M.J., Bracey, G., Gay, P.L., Lintott, C.J., Cardamone, C., Murray, P., Schawinski, K., Szalay, A.S. and Vandenberg, J. 2013 'Galaxy Zoo: motivations of citizen scientists', Astronomy Education

Review 12(1). https://doi.org/10.3847/AER2011021

Redhead, N. 2015 'Community Archaeology: a Methodology for future projects?' in Michael D. Nevell and Norman Redhead (eds) Archaeology for All. Community Archaeology in the Early 21st Century: Participation, Practice and Impact, Salford: University of Salford. 121-130.

Richardson, L-J. and Almansa-Sánchez, J. 2015 'Do you even know what public archaeology is? Trends, theory, practice, ethics', World Archaeology 47, 118. https://doi.org/10.1080/00438243.2015.1017599

Roberts, H. 2017 The Practice of Community Archaeology in the UK: A model for best practice based upon case studies from Dorset and Cambridgeshire, Unpublished PhD thesis, Bournemouth University.

Sayer, F. 2014 'Politics and the development of community archaeology in the UK', Historic Environment: Policy and Practice 5(1),

55. https://doi.org/10.1179/1756750513Z.00000000041

Sharpe, J. 2013 South Dorset Ridgeway Landscape Partnership Landscape Conservation Action Plan. https://www.dorsetaonb.org.uk/

Simpson, F.A. 2009 The values of community archaeology : a comparative assessment, Electronic Thesis. University of Exeter.

Simpson, F.A. 2010 The Values of Community Archaeology : a comparative assessment between the UK and US, Oxford:

Archaeopress. https://doi.org/10.30861/9781407306469

Simpson, F. and Williams, H. 2008 'Evaluating community archaeology in the UK', Public Archaeology 7(2), 69-90. https://doi.org/10.1179/175355308X329955

Smith, L. 2006 Uses of Heritage, Routledge. https://doi.org/10.4324/9780203602263

Smith, L. 2015 'Archaeology and communities: negotiating memory and heritage' in M. Nevell and N. Redhead (eds) Archaeology for All. Community Archaeology in the Early 21st Century: Participation, Practice and Impact, Salford: University of Salford. 3-14.

Smith, L. and Waterton, E. 2009 Heritage, Communities and Archaeology, London: Gerald Duckworth and Co. 
Stukas, A.A., Hoye, R., Nicholson, M., Brown, K.M. and Aisbett, L. 2016 'Motivations to volunteer and their associations with volunteers' well-being', Nonprofit and Voluntary Sector Quarterly 45(1), 112-32. https://doi.org/10.1177\%2F0899764014561122

Thomas, S. 2010 Community Archaeology in the UK: Recent findings, York: Council for British Archaeology. https://new.archaeologyuk.org/supporting-community-archaeologyin-the-uk [Last accessed: 18 June 2020].

Thomas, S. 2014 'Making Archaeological Heritage Accessible in Great Britain: Enter Community Archaeology' in S.Thomas and J. Lea (eds) Public Participation in Archaeology, Woodbridge: Boydell Press. 23-34.

Tully, G. 2007 'Community archaeology: general methods and standards of practice', Public Archaeology 6(3), 155-87. https://doi.org/10.1179/175355307X243645

Woodward, P.J. 1983 'The South Dorset Ridgeway: the preservation and management of the Pre-Iron Age archaeological landscape', Proceedings of the Dorset Natural History and Archaeological Society 105, 141.

Woodward, P.J. 1991 The South Dorset Ridgeway: survey and excavations, 1977-84, Dorset Natural History and Archaeological Society Monograph series, Dorchester:

Dorset Natural History and Archaeological Society. 